\title{
Strategi Pemilihan Proyek Pembangunan Pembangkit Listrik dengan Metode Analytical Hierarchy Process (AHP) di PT Pembangkitan Jawa Bali (PT PJB)
}

\author{
Heru Budi Pratomo \& Bambang Tjahjadi \\ Universitas Airlangga \\ e-mail: heru.pratomo90@gmail.com
}

\begin{abstract}
The government launched a 35,000 MW program based on the Decree of the Minister of Energy and Mineral Resources of the Republic of Indonesia especially for outside Java region as part of development of country infrastructure. To be able to continue to grow and compete, PT PJB as a company engaged in the field of electric power producers must have good investment plan, one of the investments that can be made is through participation in electric power plant development projects. The purpose of this study is to find out the influential criteria in making decisions and provide recommendations to PT PJB in the formulation of alternative priority scales for power plant development projects selection strategy. This study uses a qualitative approach with a case study approach. Samples from this study were key informants using purposive sampling and filling out questionnaires. The results of this study are the formation of 3 criteria which are the best priorities, namely generating new revenue with a weight of 0.177 , market share with a weight of 0.134 and increasing opportunities in the future with a weight of 0.127 . While the determination of the main alternative for the construction of the Power Plant Project is the Java 7 PLTU of 16.3\%, the Java 8 PLTU of $12.9 \%$ and the Java 3 PLTGU of $10 \%$.
\end{abstract}

Keywords: power generation, project management, investment, AHP

\section{PENDAHULUAN}

PT Pembangkitan Jawa Bali (PT PJB) adalah salah satu anak perusahaan dari PT PLN (Persero) yang bergerak di bidang produsen tenaga listrik. PT PJB berdiri pada tanggal 3 Oktober 1995 yang terus berkembang hingga saat ini dengan memiliki beberapa anak dan cucu perusahaan sesuai Gambar 1.1.

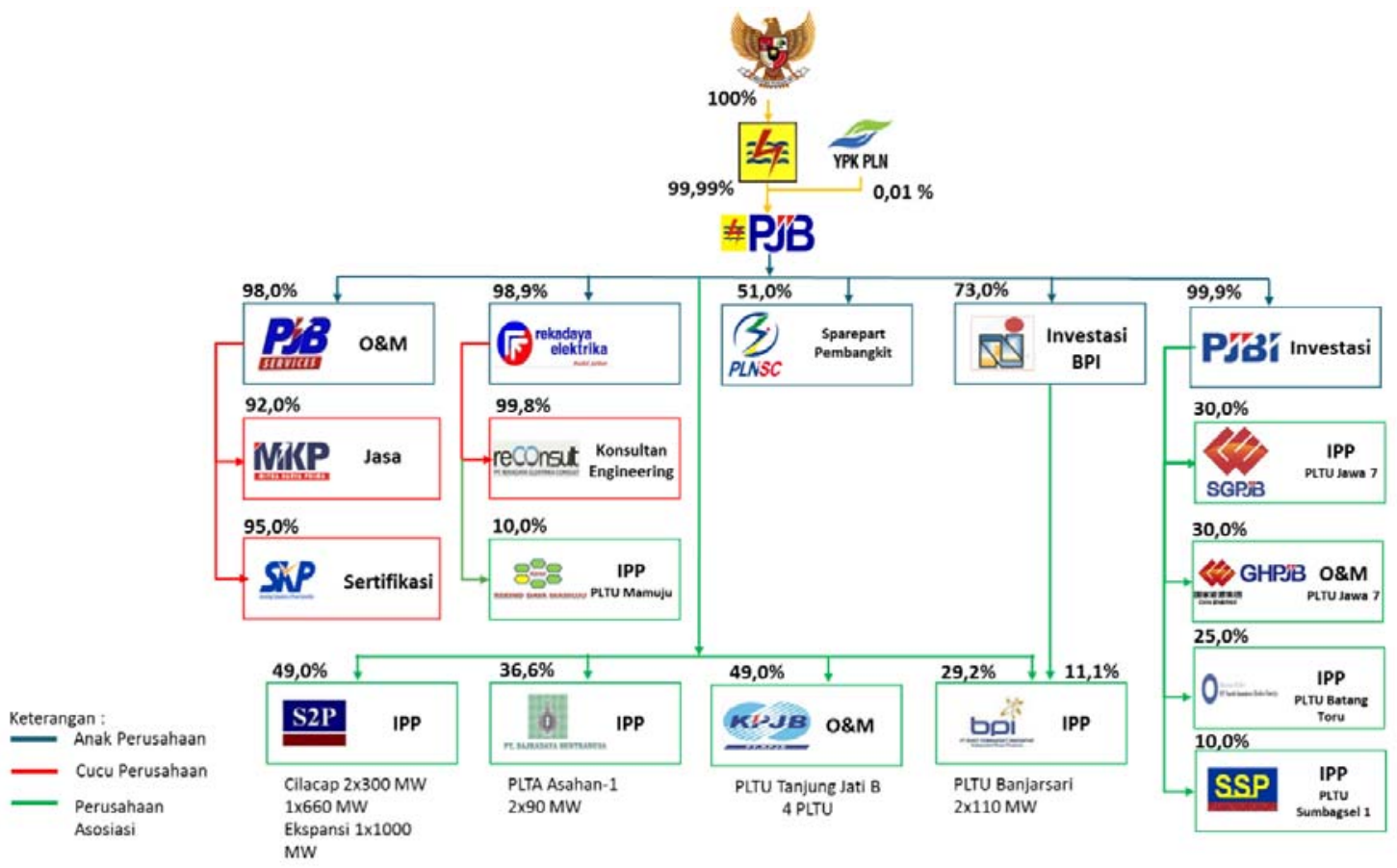


Masing-masing anak perusahaan dan perusahaan asosiasi memiliki fungsi dan peran yang berbeda-beda, namun terintegrasi untuk membantu PT PJB dalam pengembangan usaha dan rencana-rencana strategis perusahaan. Dalam menjalankan proses bisnisnya, PT PJB mengelola 9 unit pembangkit (UP) existing dengan total kapasitas daya terpasang sebesar 7.044 megawatt (MW) yaitu: UP Gresik, UP Muara Karang, UP Muara Tawar, UP Cirata, UP Brantas, UP Paiton, UP Bawean, dan UP Suppa serta 34 jasa operation and maintenance (O\&M) yang tersebar di seluruh wilayah Indonesia baik Pulau Jawa maupun luar Pulau Jawa. Berikut ini merupakan gambar dari peta wilayah operasional PT PJB di Indonesia.

Untuk dapat terus tumbuh dan bersaing, PT PJB sebagai perusahaan yang bergerak dalam bidang produsen tenaga listrik harus memiliki perencanaan yang baik dalam investasi, salah satu investasi yang dapat dilakukan adalah melalui keikutsertaan dalam proyek pembangunan tenaga listrik yang tertera di dalam RUPTL. Investasi pada proyek pembangunan tenaga listrik tersebut dapat digunakan untuk mengantisipasi penurunan nilai aset perusahaan yang diakibatkan karena unit pembangkit existing yang sudah dan akan melewati umur keekonomian pembangkit (pada umumnya, umur keekonomian pembangkit selama 30 tahun).

Di tahun 2018, banyak unit pembangkit existing PT PJB yang telah melewati batas keekonomian sehingga berdampak pada penurunan nilai aset di dalam portofolio perusahaan yang memengaruhi jumlah besaran revenue. Sangat banyak faktor yang dipergunakan oleh para pejabat untuk melakukan pertimbangan dalam pengambilan keputusan terhadap proyek pembangkit tenaga listrik sehingga menyebabkan keterlambatan realisasi pelaksanaan proyek pembangkit listrik. Adanya keterlambatan pada realisasi pelaksanaan proyek pembangkit listrik dapat memengaruhi pencapaian salah satu indikator kinerja perusahaan (batas realisasi pelaksanaan

\section{Peta Wilayah Operasional}
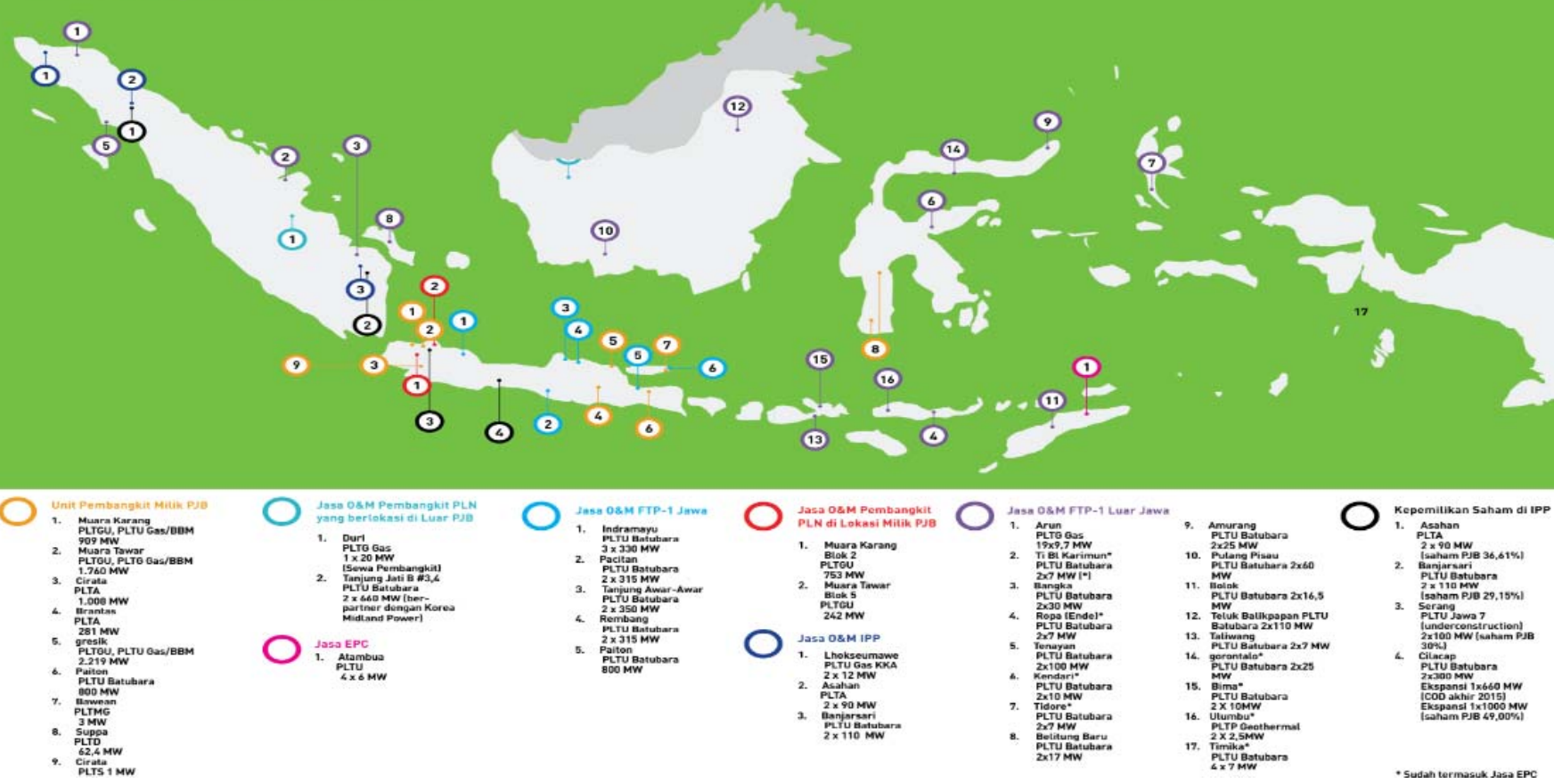


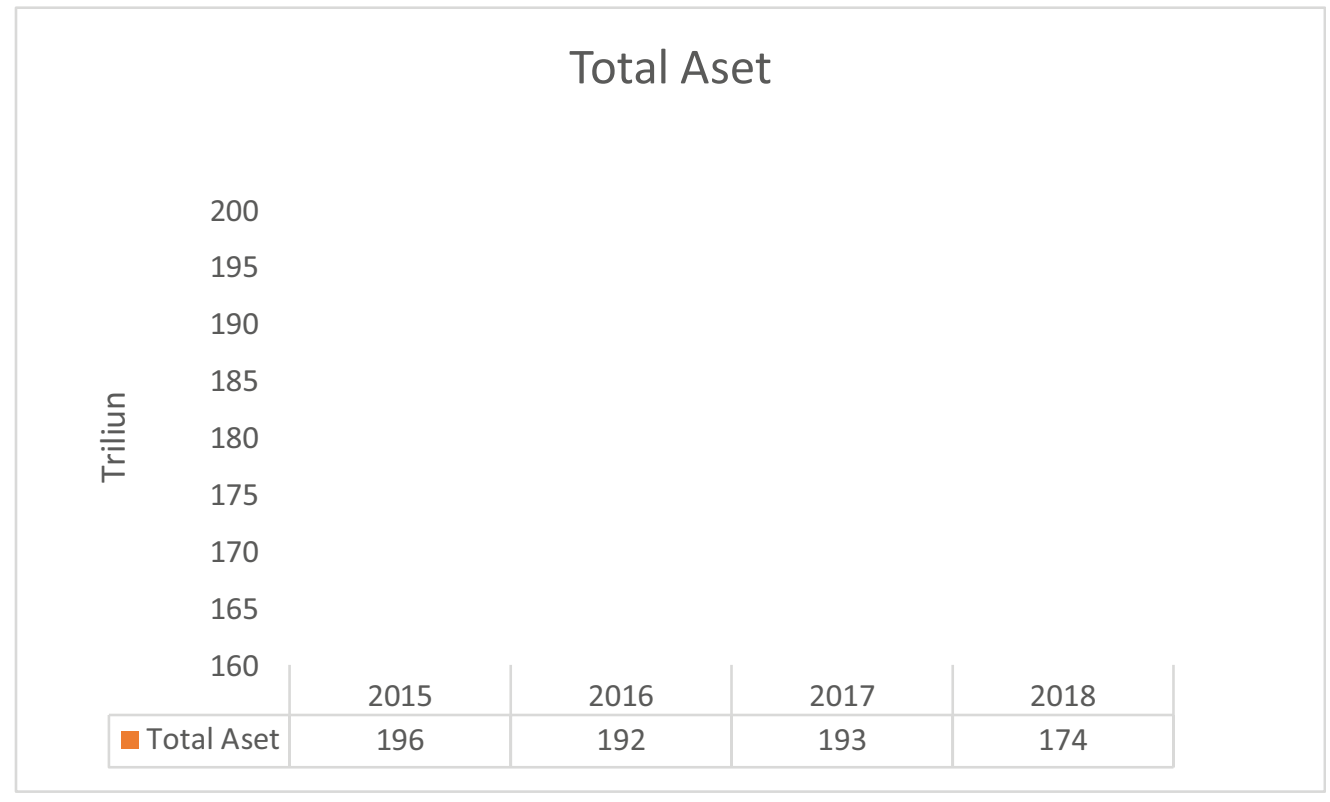

proyek pembangunan pembangkit listrik sesuai RUPTL hingga tahun 2027).

Berdasarkan gambar di atas, dapat diketahui bahwa penurunan nilai aset dari tahun $2017 \mathrm{ke}$ tahun 2018 adalah sebesar Rp 19 triliun. Nilai tersebut cukup besar bagi PT PJB sehingga harus segera dilakukan investasi melalui proyek pembangunan pembangkit listrik dalam RUPTL. Berikut ini merupakan beberapa proyek pembangunan pembangkit listrik yang direncanakan akan diambil dan dikerjakan oleh PT PJB.

\begin{tabular}{|c|c|c|c|}
\hline Nomor & $\begin{array}{l}\text { Nama } \\
\text { Proyek }\end{array}$ & $\begin{array}{c}\text { Jenis } \\
\text { Pembangkit } \\
\text { Listrik }\end{array}$ & Kapasitas \\
\hline 1 & Batang Toru & PLTA & $510 \mathrm{MW}$ \\
\hline 2 & Jawa 7 & PLTU & $2.000 \mathrm{MW}$ \\
\hline 3 & Jawa 3 & PLTGU & $800 \mathrm{MW}$ \\
\hline 4 & Sumsel 6 & PLTU & $600 \mathrm{MW}$ \\
\hline 5 & Sumbagut 1 & PLTGU & $250 \mathrm{MW}$ \\
\hline 6 & Sumbagut 3,4 & PLTGU & $750 \mathrm{MW}$ \\
\hline 7 & Dumai & PLTGU & $250 \mathrm{MW}$ \\
\hline 8 & Jawa 10 & $\begin{array}{l}\text { PLTU } \\
\end{array}$ & $660 \mathrm{MW}$ \\
\hline 9 & Jawa 9 & $\overline{\text { PLTU }}$ & $600 \mathrm{MW}$ \\
\hline 10 & Sumbagsel 1 & PLTU & $300 \mathrm{MW}$ \\
\hline 11 & Jawa 8 & PLTU & $1.000 \mathrm{MW}$ \\
\hline 12 & Sumut 2 & $\overline{\text { PLTU }}$ & $600 \mathrm{MW}$ \\
\hline \multicolumn{3}{|l|}{ Total } & $8.320 \mathrm{MW}$ \\
\hline
\end{tabular}

Diketahui bahwa jumlah total MW yang direncanakan sebesar 8.320 MW di mana jumlah total MW tersebut hanya $24 \%$ dari total keseluruhan program pemerintah yang direncanakan yaitu 35.000 MW. Rencana pembangunan ini membutuhkan dana yang sangat besar, namun dengan adanya keterbatasan dana yang ada saat ini maka PT PJB diharapkan mampu mengoptimalkan anggaran dana yang ada pada proyek pembangkit listrik yang diyakini dapat menciptakan value yang lebih bagi perusahaan. Di dalam penelitian ini akan dicari urutan skala prioritas proyek yang nantinya dapat digunakan PT PJB untuk menentukan proyek mana yang terlebih dahulu lebih penting untuk dilaksanakan. Selain itu, penelitian ini juga bertujuan untuk mencari pembobotan dari kriteria-kriteria yang dipergunakan dalam pengambilan keputusan pelaksanaan proyek pembangkit listrik.

Pada saat ini, PT PJB masih belum memiliki acuan/dasar mengenai kriteria yang dipergunakan untuk pengambilan keputusan proyek pembangunan pembangkit listrik, sehingga PT PJB tidak memiliki informasi yang cukup untuk menyusun skala prioritas pengambilan proyek pem- 
bangkit listrik yang ada dalam RUPTL. Agar penelitian dapat dilakukan dengan menggunakan metode AHP, penelitian ini akan diawali wawancara oleh peneliti dengan salah satu direksi PT PJB yang bertujuan untuk mengetahui kriteriakriteria yang dipergunakan dalam pengambilan keputusan proyek pembangunan pembangkit listrik. Dengan demikian, PT PJB akan memiliki informasi/panduan yang berisi skala prioritas masing-masing alternatif proyek pembangkit listrik untuk kemudian dapat dipergunakan sebagai dasar/acuan untuk mengalokasikan modal dalam melaksanakan proyek pembangkit listrik mana yang harus diambil terlebih dahulu.

\section{TINJAUAN PUSTAKA}

\section{Manajemen Proyek}

Manajemen proyek terdiri dari dua kata yaitu Manajemen dan Proyek. Menurut Hughes dan Cotterell (2002) Manajemen meliputi kegiatan merencanakan, mengorganisasi, mencari sumber daya, memberi instruksi, memantau kemajuan, mengontrol, memiliki inovasi dan merepresentasi. Manajemen adalah suatu proses perencanaan pengorganisasian, pengarahan dan pengawasan, usaha-usaha para anggota organisasi dan penggunaan sumber daya-sumber daya organisasi lainnya agar tercapai tujuan organisasi yang telah ditetapkan.

Manajemen proyek adalah suatu teknik yang digunakan untuk merencanakan, mengerjakan, dan mengendalikan aktivitas suatu proyek untuk memenuhi kendala waktu dan biaya proyek (Muslich, 2009). Teknik ini berorientasi pada pencapaian tujuan, di mana tujuan tersebut mungkin pembangunan gedung, pembukaan kantor baru, atau pengendalian kegiatan penelitian dan pengembangan.

\section{Kondisi Kelistrikan di Indonesia}

Kapasitas total listrik di Indonesia saat ini sekitar 52.231 megawatt (MW), dengan jumlah penduduk sekitar 250 juta jiwa. Kapasitas listrik itu untuk menerangi seluruh rumah tangga di Tanah Air yang berdasarkan data Badan Pusat Statistik (BPS) mencapai 61 juta rumah tangga. Namun, belum semua rumah tangga itu dapat menikmati setrum, terutama yang tinggal di perdesaan dan wilayah terpencil.

Dari total kapasitas pembangkit listrik di Tanah Air saat ini, pembangkit listrik tenaga uap (PLTU) yang berbahan batu bara masih mendominasi, yaitu 24.883 MW atau 48\% dari total kapasitas pembangkit di dalam negeri 52.231 MW. Posisi kedua ditempati pembangkit listrik tenaga gas dan uap (PLTGU) yang berbahan bakar gas sebesar 11.262 MW atau 22\%. Pembangkit listrik tenaga diesel (PLTD) yang berbahan bakar solar sebesar 5.771 MW atau 11\%. Pembangkit listrik tenaga gas (PLTG) dan pembangkit listrik tenaga mesin dan gas (PLTMG) sebesar $3.944 \mathrm{MW}$ atau 8\%. Sementara itu, sisanya sekitar $12 \%$ berasal dari pembangkit listrik terbarukan sebesar $6.370 \mathrm{MW}$ yang terdiri atas PLTS, PLTA, PLTMH, PLTBio, dan PLTP (www.bisnis.com, 2018).

\section{Investasi}

Investasi adalah penanaman modal untuk satu atau lebih aktiva yang dimiliki dan biasanya berjangka waktu yang panjang dengan harapan mendapatkan keuntungan di masa akan dating (Sunariyah, 2004). Menurut Jogiyanto (2010) mengatakan investasi adalah penundaan konsumsi sekarang untuk dimasukkan ke aktiva produktif selama periode waktu tertentu. Sedangkan Gitman dan Joehnk (2005) mendefinisikan investasi adalah suatu sarana di mana dana dapat 
ditempatkan dengan harapan dapat menghasilkan pendapatan secara positif dengan meningkatkan nilainya.

\section{Manajemen Strategi}

Strategi secara etimologis berasal dari kata strategic (dalam bahasa inggris) yang memiliki arti suatu cara, kiat, dan atau taktik utama (Nawawi, 2003 dalam Mappasiara, 2018). Namun, secara historis arti kata strategic bermula dari dunia militer yang kemudian lebih dikenal sebagai suatu alat atau media yang digunakan oleh para komandan militer dan atau jenderal untuk memenangkan peperangan (Mappasiara, 2018).

\section{Analytical Hierarchy Process (AHP)}

AHP yang dikembangkan oleh Saaty (1993) dapat digunakan untuk memecahkan permasalahan yang kompleks dengan aspek atau kriteria yang diambil cukup banyak (multikriteria). Kompleksitas ini disebabkan oleh struktur masalah yang belum jelas, ketidakpastian pengambil keputusan serta ketidakpastian tersedianya data statistik yang akurat atau bahkan tidak sama sekali. Ada kalanya timbul permasalahan pada saat masalah yang diamati memerlukan keputusan yang harus diambil secepatnya, tetapi variasinya rumit sehingga data tidak mungkin dapat dicatat secara numerik hanya secara kualitatif saja yang dapat diukur, yaitu berdasarkan persepsi, pengalaman dan intuisi.

Metode AHP mampu mengakomodasi kriteria-kriteria penilaian yang bersifat kualitatif dan kuantitatif serta mudah dipahami dan diterapkan dalam operating managers. Dengan AHP mampu mengidentifikasi kriteria yang dipentingkan dalam pemilihan dan evaluasi penentuan proyek pembangkit listrik. Dalam aplikasinya pihak manajemen dapat membandingkan performansi dari beberapa proyek secara efektif dan dapat menetapkan proyek mana yang terbaik.

\section{PERUMUSAN MASALAH}

Berdasarkan uraian latar belakang permasalahan di dalam penelitian, maka pertanyaan penelitian yang akan dijawab melalui penelitian ini adalah "bagaimana PT PJB dapat melaksanakan pembangunan proyek pembangit listrik dalam RUPTL dengan tepat waktu untuk menambah nilai aset dan revenue perusahaan agar dapat terus bersaing di bidang produsen tenaga listrik?"

\section{METODE PENELITIAN}

Penelitian ini dikategorikan sebagai penelitian kualitatif, karena data yang diperoleh dalam penelitian ini berupa data kualitatif (data deskriptif). Moleong (2012) mengemukakan bahwa metodologi kualitatif merupakan prosedur penelitian yang menghasilkan data deskriptif berupa katakata tertulis maupun lisan dari orang-orang dan perilaku yang diamati.

\section{Sampel dan Teknik Pengambilan Sampel}

Sampel yang digunakan dalam penelitian ini adalah key informan (informan kunci) yaitu orang-orang yang sangat memahami organisasi dan memiliki kepentingan sesuai dengan informasi yang dibutuhkan dalam penelitian ini. Penentuan informan kunci ditentukan menggunakan purposive sampling. Pada penelitian ini akan dilaksanakan wawancara dengan beberapa key informan yang mengetahui terkait proyek pembangkit listrik PT PJB yaitu: direktur niaga, direktur operasi 1, direktur operasi 2, dan direktur keuangan yang dianggap memahami terkait proyek pembangkit listrik. Penentuan informan 
menggunakan teknik purposive sampling, yaitu peneliti memilih informan berdasarkan pertimbangan yang disesuaikan dengan tujuan penelitian.

\section{Lokasi Penelitian}

Penelitian ini dilakukan di PT Pembangkit Jawa Bali.

\section{Teknik Analisis}

Pengolahan data dalam penelitian ini dapat dilakukan dengan beberapa tahapan yaitu:

1. Penentuan bobot kriteria menggunakan AHP Langkah pertama yang dilakukan adalah mengetahui kriteria yang berpengaruh terhadap pengambilan keputusan proyek pembangkit listrik PT PJB dan menyebarkan kuesioner pada key informan. Langkah selanjutnya memasukkan data hasil dari kuesioner dengan menggunakan metode AHP yang bertujuan mencari bobot dari masing-masing kriteria. Dimulai dari menyusun matriks perbandingan berpasangan, dilanjutkan pengecekan konsistensi sampai didapat bobot yang diinginkan. Pembobotan terhadap kriteria-kriteria diolah menggunakan software expert choice.

2. Reduksi data

Reduksi data merupakan salah satu dari teknik analisis data kualitatif. Reduksi data adalah bentuk analisis yang menajamkan, menggolongkan, mengarahkan, membuang yang tidak perlu dan mengorganisasi data sedemikian rupa sehingga kesimpulan akhir dapat diambil. Langkah reduksi data melibatkan beberapa tahap.

3. Penyajian data

Penyajian data merupakan salah satu dari teknik analisis data kualitatif. Penyajian data adalah kegiatan ketika sekumpulan informasi disusun, sehingga memberi kemungkinan akan adanya penarikan kesimpulan. Penyajian data melibatkan langkah-langkah mengorganisasikan data, yakni menjalin kelompok data yang satu dengan kelompok data lainnya sehingga seluruh data yang dianalisis benarbenar dilibatkan dalam satu kesatuan karena dalam penelitian kualitatif data biasanya beraneka ragam perspektif dan terasa bertumpuk maka penyajian data pada umumnya diyakini sangat membantu proses analisis Bentuk penyajian data kualitatif berupa teks naratif (berbentuk catatan lapangan), matriks, grafik, jaringan dan bagan.

4. Penarikan kesimpulan dan verifikasi Penarikan kesimpulan merupakan salah satu dari teknik analisis data kualitatif. Penarikan kesimpulan adalah hasil analisis yang dapat digunakan untuk mengambil tindakan. Pada dasarnya mengimplementasikan prinsip induktif dengan mempertimbangkan pola-pola data yang ada dan atau kecenderungan dari display data yang dibuat. Ada kalanya kesimpulan telah tergambar sejak awal, namun kesimpulan final tidak pernah dapat dirumuskan secara memadai tanpa peneliti menyelesaikan analisis seluruh data yang ada.

\section{ANALISIS DAN PEMBAHASAN HASIL PENE- LITIAN}

\section{Gambaran Umum Objek Penelitian}

PT Pembangkitan Jawa-Bali (PJB) merupakan salah satu anak perusahaan dari PT PLN (Persero). Sejarah PJB berawal dari restrukturisasi yang dilakukan PLN (Perusahaan Listrik Negara) pada tahun 1982, dengan melakukan pemisahan unit sesuai fungsinya, yaitu Unit PLN Distribusi dan Unit PLN Pembangkitan serta Unit PLN Penyaluran. Selanjutnya pada 3 Okto- 
ber 1995, PLN melakukan restrukturisasi khusus bidang pembangkitan dengan mendirikan dua anak perusahaan, yaitu PT PLN Pembangkitan Tenaga Listrik Jawa-Bali I yang berkantor pusat di Jakarta dan PT PLN Pembangkitan Tenaga Listrik Jawa-Bali II yang berkantor pusat di Surabaya. Pada tahun 2000, PT PLN Pembangkitan Tenaga.

\section{Identifikasi Kriteria pada Penentuan Proyek Pem- bangunan Pembangkit Listrik}

Identifikasi kriteria merupakan salah satu tahapan yang penting karena dapat diketahui kriteria yang digunakan dalam penentuan proyek pembangunan listrik di PT PJB. Penelitian ini berfokus pada identifikasi kriteria pada proyek pembangunan listrik, termasuk juga mengetahui alternatif yang tepat proyek mana yang akan dilakukan pembangunan kemudian akan dilakukan strategi penentuan pembiayaan yang tepat sehingga dapat menghilangkan/mengurangi dampak dari risiko. Dari hasil wawancara dengan responden, dokumen internal perusahaan dan pengamatan langsung didapatkan hasil kriteria yang menjadi dasar sebagai penentuan proyek pembangunan listrik, dengan rincian masingmasing yaitu sebagai berikut.

1. Kesesuaian Proyek dengan arah strategis RJPP PJB

Proyek Pembangkit Listrik yang akan dilaksanakan oleh PJB merupakan salah satu strategi untuk memperluas pasar (ekspansi pasar). Di dalam kriteria ini, proyek pembangkit listrik yang ada diharapkan mampu untuk menciptakan value dalam mencapai sasaran strategis yang telah ditentukan oleh PJB.

2. Proyek akan memberikan pengenalan teknologi baru dan proven kepada PJB

Kriteria ini menjadi salah satu pertimbangan dalam keputusan pengambilan proyek Pem- bangkit Listrik karena sebagai perusahaan yang terus berkembang, PJB menginginkan agar proyek Pembangkit Listrik yang nantinya akan diambil dapat membantu perusahaan untuk mengenalkan teknologi terbaru yang ada di pasar.

3. Peningkatan market share

Salah satu faktor penting bagi semua perusahaan adalah peningkatan market share. Begitu juga PJB, dalam hal peningkatan market share pertimbangan akan lebih menitikberatkan pada jumlah kapasitas produksi dari pembangkit listrik (mega watt).

4. Generating new revenue

Kriteria ini diharapkan untuk menambah pendapatan baru dari proyek Pembangkit Listrik yang akan dipilih. Pada umumnya, perusahaan membagi ke dalam tiga bagian yaitu proyek Pembangkit Listrik dengan revenue kecil ( $<\mathrm{Rp} 5 \mathrm{M} /$ tahun), sedang ( $\mathrm{Rp} 5-$ $10 \mathrm{M} /$ tahun), dan tinggi ( $>\mathrm{Rp} 10 \mathrm{M} /$ tahun).

5. Dukungan pemangku kepentingan dan/atau stakeholder

Untuk membantu terlaksananya penyelesaian proyek pembangkit listrik, tentunya harus ditinjau dari adanya dukungan dari pemerintah (pusat atau daerah) ataupun adanya surat penugasan pelaksanaan proyek kepada PJB.

6. Ketersediaan jaminan pemerintah atau insentif dari pemerintah

Proyek pembangkit listrik membutuhkan dana yang sangat besar, sehingga risiko jika terjadi kegagalan pelaksanaan proyek akan berdampak pada kelancaran kondisi keuangan perusahaan. Oleh karena itu, pemilihan Proyek Pembangkit Listrik sebaiknya mempertimbangkan apakah proyek tersebut mendapatkan jaminan dan insentif dari pemerintah dan perusahaan harus berusaha sebaik mungkin untuk mendapatkannya. 
7. Potensi Risiko kegagalan proyek Salah satu upaya yang dilakukan PJB untuk dapat terus maju dan bersaing di dalam bisnis produksi tenaga listrik adalah dengan melakukan investasi, di dalam hal ini adalah investasi pada proyek pembangkit listrik. Dalam setiap investasi yang dilakukan akan terdapat suatu risiko kegagalan, karena besaran modal yang dibutuhkan untuk proyek pembangkit listrik sangat besar maka PJB harus memilah potensi risiko kegagalan proyek. Untuk menganalisis potensi risiko tersebut dapat melalui data historis proyek sejenis yang telah sukses di Indonesia, kemudian sudah ada regulasi yang mengatur (misalnya dalam bidang penetapan tariff), adanya dukungan dari masyarakat sekitar, dan faktor lain yang dapat memengaruhi potensi risiko kegagalan proyek.

8. Peluang pengembangan di masa datang Demi mencapai continuous improvement dan menambah investasi pada unit existing, maka Proyek Pembangkit Listrik yang akan dipilih harus dapat memberikan nilai tambah dan memiliki peluang pengembangan di masa mendatang (adanya opsi upgrading dan retrovit pembangkit listrik).

9. Peningkatan core competence

Core competence merupakan bagian yang menjadi kriteria yang disyaratkan dalam penentuan proyek. Proyek yang nantinya dihasilkan paling tidak memiliki core competence sehingga bisa mendapatkan hasil yang diinginkan oleh perusahaan.

10. Kesiapan kompetensi

Proyek Pembangkit Listrik yang akan dipilih memiliki berbagai macam jenis sehingga membutuhkan kompetensi sumber daya manusia yang juga berbeda. Kesiapan kompetensi SDM dalam menjalankan pembangkit listrik dengan jenis tertentu akan menjadi kunci salah satu kriteria penting dalam indikator operasi pembangkit listrik yaitu keandalan. Oleh karena itu, keputusan pemilihan proyek pembangkit listrik juga harus mempertimbangkan kesiapan SDM yang dimiliki.

11. Kesiapan infrastruktur

Infrastruktur juga menjadi modal yang cukup penting bagi penentuan proyek PT Pembangkitan Jawa Bali. Dengan infrastruktur yang memadai akan memudahkan pembangunan dan sesuai dengan target waktu yang ditetapkan. Selain itu kesiapan infrastruktur di sini juga terkait dengan keandalan pasokan bahan bakar utama yang digunakan oleh pembangkit listrik.

12. Lokasi proyek (keadaan geografis) sesuai dengan target PJB

Lokasi juga memegang hal yang penting dalam penentuan pemilihan proyek pembangkit listrik. Dalam hal ini lokasi proyek akan secara berurutan akan diprioritaskan pada Pulau Jawa; Sumatera, Kalimantan, dan Sulawesi; Maluku, Papua, Nusa Tenggara Timur, dan Nusa Tenggara Barat.

Alternatif yang digunakan dalam penentuan proyek berdasarkan internal perusahaan sebanyak 12 nama proyek sebagai berikut.

\begin{tabular}{|c|c|c|c|}
\hline Nomor & $\begin{array}{l}\text { Nama } \\
\text { Proyek }\end{array}$ & $\begin{array}{c}\text { Jenis } \\
\text { Pembangkit } \\
\text { Listrik }\end{array}$ & Kapasitas \\
\hline 1 & Batang Toru & PLTA & $510 \mathrm{MW}$ \\
\hline 2 & Jawa 7 & PLTU & $2.000 \mathrm{MW}$ \\
\hline 3 & Jawa 3 & PLTGU & $800 \mathrm{MW}$ \\
\hline 4 & Sumsel 6 & $\begin{array}{l}\text { PLTU } \\
\end{array}$ & $600 \mathrm{MW}$ \\
\hline 5 & Sumbagut 1 & $\begin{array}{l}\text { PLTGU } \\
\end{array}$ & $250 \mathrm{MW}$ \\
\hline 6 & Sumbagut 3,4 & PLTGU & $750 \mathrm{MW}$ \\
\hline 7 & Dumai & PLTGU & $250 \mathrm{MW}$ \\
\hline 8 & Jawa 10 & PLTU & $660 \mathrm{MW}$ \\
\hline 9 & Jawa 9 & PLTU & $600 \mathrm{MW}$ \\
\hline 10 & Sumbagsel 1 & PLTU & $300 \mathrm{MW}$ \\
\hline 11 & Jawa 8 & PLTU & $1.000 \mathrm{MW}$ \\
\hline 12 & Sumut 2 & PLTU & $600 \mathrm{MW}$ \\
\hline \multicolumn{3}{|l|}{ Total } & $8.320 \mathrm{MW}$ \\
\hline
\end{tabular}


Hasil Pembobotan Skala Prioritas Tingkat Kepentingan Kriteria

Proses pengolahan data untuk AHP menggunakan bantuan software expert choice yang dikembangkan oleh Saaty (1993). Pada pengolahan data dilakukan pengujian konsistensi peni- laian. Apabila nilai ratio konsistensi di atas 10\% (CR $>10 \%)$, penilaian dilakukan pengulangan sampai memperoleh tingkat konsistensi yang baik $(\mathrm{CR}<10 \%)$ selanjutnya diperoleh bobot prioritas. Berdasarkan hasil pengolahan data menggunakan expert choice diperoleh bobot prioritas dan rasio konsistensi pada tabel berikut ini.

\begin{tabular}{|l|c|}
\hline \multicolumn{1}{|c|}{ Kriteria } & $\begin{array}{c}\text { Bobot } \\
\text { Prioritas }\end{array}$ \\
\hline Kesesuaian Proyek dengan arah strategis RJPP PJB & 0,06 \\
\hline $\begin{array}{l}\text { Proyek akan memberikan pengenalan teknologi baru } \\
\text { dan proven kepada PJB }\end{array}$ & 0,034 \\
\hline Peningkatan market share & 0,134 \\
\hline Generating new revenue & 0,177 \\
\hline Dukungan Pemangku Kepentingan dan/atau stakeholder & 0,057 \\
\hline Ketersediaan jaminan pemerintah atau insentif dari pemerintah & 0,020 \\
\hline Potensi Risiko kegagalan proyek & 0,040 \\
\hline Peluang pengembangan di masa datang & 0,127 \\
\hline Peningkatan core competence & 0,114 \\
\hline Kesiapan kompetensi & 0,070 \\
\hline Kesiapan infrastruktur & 0,058 \\
\hline Lokasi proyek (keadaan geografis) sesuai dengan target PJB & 0,107 \\
\hline
\end{tabular}

\section{Analisis Model AHP dan Data Hasil Penelitian}

Proses penilaian yang dilakukan dalam penelitian ini didasarkan pada proses analitik, di mana penelitian dilakukan secara judgment. Dalam penelitian ini, responden terpilih yang melakukan penilaian di mana responden dinilai memiliki kontribusi besar dalam penentuan pembangunan proyek pembangkit listrik pada PT PJB. Hasil penelitian yang diproses dalam pengolahan AHP merupakan rata-rata dari empat orang responden.
Pada pengolahan data dilakukan pengujian konsistensi penilaian. Suatu penilaian perbandingan berpasangan dikatakan konsisten jika CR tidak lebih dari 0,1. Berdasarkan pengolahan penilaian perbandingan berpasangan didapatkan rasio konsistensi penilaian yang telah dilakukan para responden sebesar 0,09. Hal ini menunjukkan bahwa penilaian yang dilakukan sudah cukup konsisten. Berikut ini merupakan analisis terhadap nilai bobot pada kriteria yang dihasilkan melalui AHP dengan bantuan software expert choice.

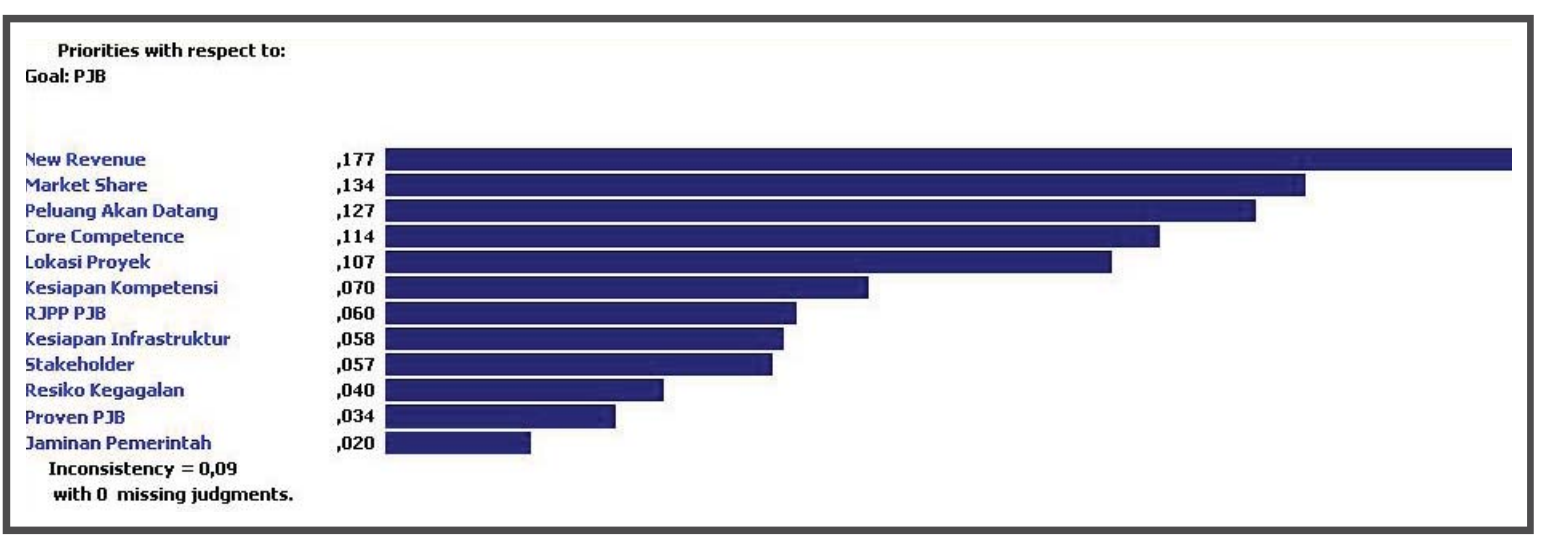


Selain dilihat dari kriteria, hal lain yang perlu dibahas yaitu dari alternatif yang digunakan dalam penelitian ini. Berdasarkan hasil dari analisis dengan AHP, maka dapat di analisis berdasarkan alternatif, di antaranya sebagai berikut.

Dilihat dari hasil penilaian akhir didapat bahwa PLTU Jawa 7 menjadi prioritas utama dalam penentuan proyek pembangunan pembangkit listrik dengan nilai sebesar 16,3\%. Jawa menjadi prioritas utama karena tingkat konsumsi listrik di Jawa sangat tinggi, hal ini bisa dilihat dari pengertian pada kriteria lokasi dapat dijelaskan bahwa lokasi Jawa menjadi hal yang utama dalam proyek pembangunan, kemudian disusul oleh Sumatera, Kalimantan, dan Sulawesi; Maluku, Papua, Nusa Tenggara Timur, dan Nusa Tenggara Barat. PLTU Jawa 7 merupakan proyek pembangunan dengan kapasitas yang paling besar yaitu $2000 \mathrm{MW}$, mengingat konsumsi listrik yang sangat tinggi pada pulau Jawa. Selain itu PLTU Jawa 8 dengan kapasitas 1000 MW dengan prioritas kedua untuk penentuan proyek, selanjutnya ada PLTGU Jawa 3 dengan kapasitas 800 MW sebagai prioritas 3, PLTU Jawa 10 dengan kapasitas $660 \mathrm{MW}$ menempati prioritas keempat dan PLTU Jawa 9 dengan kapasitas 600 MW sebagai prioritas kelima. Hal ini bisa dilihat dari peringkat alternatif yang diprioritaskan mulai dari 1 sampai 5 merupakan pembangunan yang berlokasi di Pulau Jawa.

Selain Pulau Jawa, alternatif yang menjadi prioritas adalah di daerah Sumatera. Pada area Sumatera menempati prioritas selanjutnya yang terdiri dari Sumatera Utara 3 dan 4 dengan kapasitas $750 \mathrm{MW}$, Sumatera Utara dengan kapasitas $600 \mathrm{MW}$ serta Sumatera Selatan dengan kapasitas 600 MW. Dilihat dari kapasitas yang akan dibangun pembangkit listrik, Sumatera memiliki potensi untuk meningkatkan market share bagi perusahaan. Hal ini mengacu pada Sumatera juga memiliki tingkat konsumsi listrik ter- tinggi setelah Pulau Jawa. Tingginya konsumsi listrik pada Pulau Sumatera diharapkan untuk menambah pendapatan baru dari proyek Pembangkit Listrik yang akan dipilih. Pada umumnya, perusahaan membagi ke dalam tiga bagian yaitu proyek Pembangkit Listrik dengan revenue kecil (<Rp $5 \mathrm{M} /$ tahun), sedang (Rp 5-10 M/tahun), dan tinggi (>Rp $10 \mathrm{M} /$ tahun).

Selanjutnya, secara berturut-turut ada alternatif PLTGU Sumatera Utara dengan kapasitas 250 MW, PLTU Dumai dengan kapasitas 250 MW, PLTU Sumatera Selatan 1 dengan kapasitas 300 MW dan PLTA Batang dengan kapasitas 510 MW. Prioritas ini menjadi prioritas yang terakhir sebagai pilihan dalam pembangunan pembangkit listrik, karena daerah tersebut sebagai peluang yang akan datang bagi perusahaan. Selain itu dilihat dari kapasitas yang akan dibangun tidak membutuhkan investasi yang besar karena dengan kapasitas kurang lebih $250 \mathrm{MW}$ akan menghasilkan revenue kecil yaitu senilai kurang dari $5 \mathrm{M}$ per tahun.

\section{SIMPULAN DAN SARAN}

\section{Simpulan}

Dari hasil penelitian dapat diambil kesimpulan sebagai berikut.

1. Mengidentifikasi kriteria yang menjadi pembangunan proyek pembangkit listrik serta memberikan bobot terhadap masing-masing yang didapat dengan menggunakan software Expert Choice.

a. Generating new revenue dengan bobot sebesar 0,177 .

b. Market share dengan bobot sebesar 0,134.

c. Peningkatan Peluang pengembangan di masa datang mempunyai bobot 0,127.

d. Peningkatan core competence dengan bobot sebesar 0,114 . 
e. Peningkatan Lokasi proyek (keadaan geografis) sesuai dengan target PJB memiliki bobot 0,107.

f. Peningkatan Kesiapan kompetensi dengan bobot 0,070 .

g. Peningkatan kesesuaian proyek dengan arah strategis RJPP PJB bernilai 0,060

h. Peningkatan Kesiapan infrastruktur bernilai 0,058 .

i. Peningkatan dukungan pemangku kepentingan dan/atau stakeholder dengan bobot sebesar 0,057 .

j. Peningkatan potensi risiko kegagalan proyek bernilai 0,040 .

k. Peningkatan proyek akan memberikan pengenalan teknologi baru dan proven kepada PJB bernilai 0,034.

1. Peningkatan Ketersediaan jaminan pemerintah atau insentif dari pemerintah didapatkan nilai sebesar 0,020 .

2. Penentuan alternatif pembangunan proyek pembangkit listrik dan kemudian meranking alternatif yang didapat dengan menggunakan software Expert Choice.

a. PLTU Jawa 7 sebesar 16,3\%

b. PLTU Jawa 8 sebesar $12,9 \%$

c. PLTGU Jawa 3 sebesar $10 \%$

d. PLTU Jawa 10 sebesar 9,6\%

e. PLTU Jawa 9 sebesar 9,1\%

f. PLTGU Sumatera 3 sebesar 7,9\%

g. PLTU Sumatera Utara 2 dan PLTU Sumatera Selatan 6 sebesar 6,8\%

h. PLTGU Sumatera 1 sebesar 5,7\%

i. PLTGU Dumai sebesar 5,6\%

j. PLTU Sumatera Selatan 1 sebesar 5,3\%

k. PLTA Batang sebesar 4\%

\section{Saran}

Berikut adalah saran yang dapat saya berikan dalam penelitian ini.
1. Perusahaan dapat meningkatkan market share mereka dengan melakukan pembangunan di wilayah selain Jawa dan Sumatera, karena berpotensi meningkatkan pendapatan yang baru bagi perusahaan.

2. Bagi peneliti selanjutnya yang berniat melakukan penelitian dapat mengembangkan metode yang lain. Oleh sebab itu, penulis menyarankan untuk peneliti selanjutnya mencoba mengembangkan metode yang digunakan, misalnya dengan melakukan optimasi model persamaan, di mana dapat di cari dengan menggunakan goal programming untuk menentukan model persamaan pada PT Pembangkitan Jawa-Bali (PJB).

\section{DAFTAR RUJUKAN}

Allen, M.S. 2000. Business Portofolio Management. Jakarta: Penerbit Erlangga.

Halim, A. 2005. Analisis Investasi, Edisi Kedua. Jakarta: Salemba Empat, Alfabeta.

Hughes, B dan Cotterel, M. 2002. Software Project Management, Edisi ke-3. London: McGraw-Hill.

Jones, C.P. 2003. Investments: Analysis \& Management. New York: John Wiley \& Sons. Inc.

Kerzner, H. 1998. Project Management, A System Approach to Planning, Schedulling \& Controlling, Six Edition.

Lestari, R.M., Baihaqi, I., \& Persada, S.F. 2018. Praktik Manajemen Energi pada Industri Manufaktur. Jurnal Teknik ITS Vol. 7, No. 1.

Moleong, Lexy J. 2012. Metodologi Penelitian Kualitatif. Bandung: PT Remaja Rosdakarya.

Muslich, M. 2009. Metode Pengambilan Keputusan Kuantitatif. Jakarta: Bumi Aksara. 
Purnomo, H. 2004. Pengantar Teknik Industri. Yogyakarta: Graha Ilmu.

Prasetya, H. \& Lukiastusi, F. 2009. Manajemen Operasi. Yogyakarta: Media Pressindo.

Saaty, L. 1993. Pengambilan Keputusan bagi Para Pemimpin. Proses Hierarki Analitik untuk Pengambilan Keputusan dalam Situasi yang Kompleks, Seri Manajemen No. 134. Jakarta: LPPM dan PT Pustaka Binaman Pressindo.
Santosa, B. 2009. Manajemen Proyek: Konsep o Implementasi. Yogyakarta: Graha Ilmu. Schwalbe, K. 2004. Information Technology Project Management, Edisi ke-4. Boston Massachusetts: Course Technology.

Setiawan, H., Anggraeni. S.K., \& Purnamasari, F. 2013. Analisis Penentuan Rating Risiko Proyek PT XYZ Metode Analytical Hierarchy Process (AHP). Seminar Nasional IENACO. 